\title{
迅速・高感度測定をめざしたガス分析装置の開発と質量スペクトルの整形
}

\author{
秦野 歳久 $* 1 \cdot$ 平塚 一*1. 阿部 哲也*1
}

\section{Development of Gas Analyzer to Aim for Speed and High Sensitivity and Shaping of Mass Spectrum}

\author{
Toshihisa HATANO*1, Hajime HIRATSUKA*1 and Tetsuya ABE*1 \\ *1 Industrial Collaboration Promotion Department, Japan Atomic Energy Agency, \\ 2-4 Shirane Shirakata, Tokai-mura, Naka-gun, Ibaraki 319-1195, Japan
}

(Received October 1, 2010, Accepted May 20, 2011)

\begin{abstract}
The gas analysis system with EI-QMS (Electron Ionization-Quadrupole Mass Spectrometer) developed by Japan Atomic Energy Agency (JAEA) is commercially available from a private company through a technology transfer. The system has already been used to a medical field such as breath analysis, a quality control of automobile casting parts made of recycled aluminum, and a measurement of food aromatic elements emitting from vegetable and sake. A pulse gas sampling and a continuous evacuation were integrated to the system that aimed at obtaining high sensitive and stable mass spectrum and accomplishing fast measurement prepared for $100 \%$ inspection of industrial parts and various foods. As a result, the system achieved a background pressure of $10^{-7} \mathrm{~Pa}$ and a background ion current of $10^{-13} \mathrm{~A}$ in the normal condition. An intensity of the mass spectrum decreased linearly with decreasing the pressure by the continuous evacuation, therefore, the intensity of the mass spectrum was corrected by the pump down curve, which is a new mathematical approach equivalent to a constant pressure curve. It was confirmed that the system had the sensing performance of $100 \mathrm{ppb}$.
\end{abstract}

\section{1. はじめに}

核融合の研究開発においてプラズマ中の微量ガス成分を迅 速かつ高感度に測定するための四重極型質量分析計（Quadrupol Mass Spectrometer, 以下 QMS と略する)1)を用いた ガス分析装置 2) 開発した。 現在この装置は，民間企業に技 術移転され，実用機として市販されている3 . 本装置は，大 気圧のガスの質量スペクトルを高感度かつ再現性良く迅速に 測定することができるため，この特長を活かしてこれまでに 呼気分析などの医療分野をはじめ, 再生アルミ材鋳物部品の 品質管理に適用した自動車分野, レタスヤ1やアシタバヤ2など の野菜や日本酒`3の香り成分を測定した食品分野など様々な 分野に利用されている.

QMS を用いた通常のガス測定装置では, 試料ガスの状態 を一定にして精密な測定を抢こなってきた。 なかでも圧力を 一定に保持するためには, リークバルブ等により排気コンダ クタンスを精細に制御するなどの技術課題がある.さらに測 定室内に残留している測定済みガスや真空容器内壁からの放 出ガス等によるバックグラウンド圧力の不安定性が質量スペ クトルの再現性抢よび安定性に大きく影響して抢り, 極力低 減する必要がある。

本ガス分析装置は, 工業部品や食品などの全数検査に対応 できる迅速測定で質量スペクトルを高感度かつ安定して測定 できることを目指して, 間欠ガス注入と連続排気機能を組み

*1 日本原子力研究開発機構産学連携推進部（=319-1195 茨城県 那珂郡東海村白方白根 2-4)

${ }^{\dagger 1}$ : 「農商工等連携事業計画」第 1 号認定（2009.9.19）経済産業 省・農林水産省

$\uparrow 2$ : 「農商工等連携事業計画」第 8 号認定 (2010.10.5) 経済産業 省・農林水産省

†3: 日本酒の香り分析を記録した映像で映文連アワード2009ソー シャル・コミュニケーション部門優秀賞と第51回科学技術映 像祭 科学技術教養部門優秀賞を受賞.
合わせた．連続排気する高感度ガス分析装置に試料ガスを注 入すると, 圧力と共に減少する質量スペクトルが得られる.

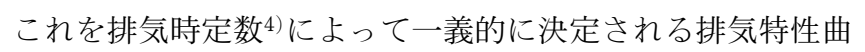
線によって補正して圧力一定の場合に対応するように数学的 手法で整形し，質量スペクトルを分析評価する.

ここでは本装置によるガスの測定方法および排気時定数か ら整形した質量スペクトルの分析例を示す.

\section{2. ガス測定}

\section{1 装置}

Fig. 1 にガス測定装置の外観を示す。本装置は, 電子イ オン化四重極質量分析計 (Pfeiffer Vacuum 製 QMS200, 以 下, $\mathrm{EI}^{5)}-\mathrm{QMS}$ と略する), 真空容器, ターボ分子ポンプ $(60 \mathrm{l} / \mathrm{min})$, ダイヤフラムポンプ $(15 \mathrm{l} / \mathrm{min})$, 試料ガス導 入部などで構成される. 真空排気系は 2 組, 測定部と試料

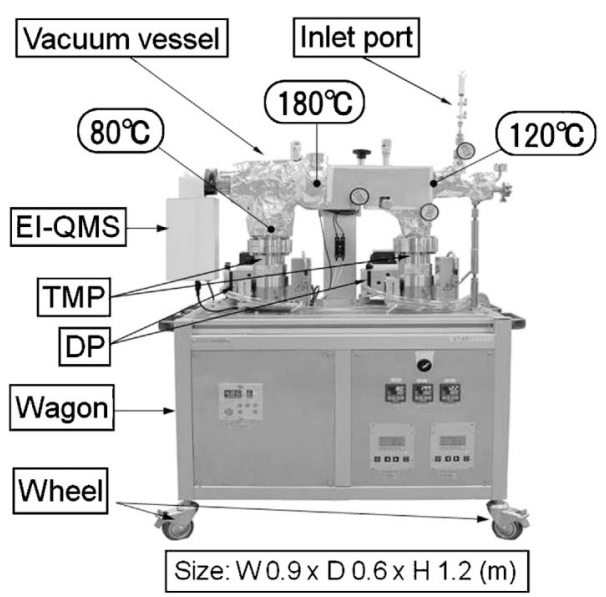

Fig. 1 Side view of the gas analyzer within an EI-QMS. The analyzer is composed of a vacuum vessel, an EI-QMS, two TMPs, two diaphragm pumps, an gas inlet port and a wagon with wheels. 
Table 1 Performance of EI-QMS

\begin{tabular}{l|c}
\hline \hline Sensitivity $(\mathrm{A} / \mathrm{Pa})$ & $2.9 \times 10^{-6 *}$ \\
without SEM & $1.3 \times 10^{-2}$ \\
with SEM $(1050 \mathrm{~V})$ & \\
\hline Condition & 0.03 \\
Scan velocity $(\mathrm{sec} / \mathrm{amu})$ & $100 \% \mathrm{~N}_{2}$ \\
Test gas & Pulse \\
\hline Inlet gas & \\
\hline
\end{tabular}

* : Factory inspection $4.3 \times 10^{-6}$

ガス導入部に取り付けられている. 外形寸法は幅 $0.9 \mathrm{~m}$, 奥 行き $0.6 \mathrm{~m}$, 高さ $1.2 \mathrm{~m}$, 総重量は約 $40 \mathrm{~kg}$ であり, 可搬性を もたすためにキャスターを取り付けた.

EI-QMS は，一般的に測定部の試料ガス圧を $10^{-2} \mathrm{~Pa}$ 以下 にしなければならず，大気圧の試料ガスを測定する場合，差 動排気を打こなって $10^{-2} \mathrm{~Pa}$ 以下にしている．さらに容器内 の残留ガスを極力低減化するためガス導入部から測定部にか けて $120^{\circ} \mathrm{C}$ から $180^{\circ} \mathrm{C}$ に保持してベーキングし，連続排気の 状態で〜 $10^{-7} \mathrm{~Pa}$ に維持して測定する．その結果，質量スぺ クトルのバックグラウンドノイズレベルは $<1 \times 10^{-13} \mathrm{~A}$ と なった. Table 1 にガス測定時の EI-QMS の性能を示す.

\section{2 ガス導入}

1 回のガス測定手順は, 連続排気した状態で一定量の試料 ガスを 1 回だけ注入し，EI-QMS で所要の質量数まで測定 する. 本装置はそのまま到達圧力まで連続排気し, 次の測定 に備える. 試料ガスの採取用具は使い回しによる過去の測定 済反残留ガスによる污染（履歴污染ガス）等の影響を低減さ せるために医療用注射針, 注射器, 三方活栓を試料ガス毎に 新しいものを使用した．試料ガスが入った注射器を直接，ガ 又導入口に三方活栓を経由して接続した. 1 回の試料ガス量 は $0.2 \times 10^{-6} \mathrm{~m}^{3}$ (1 atm) である. 三方活栓から測定室の間 は連続排気されている，試料ガスを注入するといったんガス 圧は $10^{-4} \mathrm{~Pa}$ 台に上昇し，その後排気ポンプにより指数関数 的に排気され減少する．そのガス圧は下記の指数関数で表す ことができる4).

$$
\mathrm{P}=\mathrm{P}_{0} \exp (-\mathrm{t} / \tau)
$$

ここで $\mathrm{P}$ は压力 $(\mathrm{Pa}), \mathrm{P}_{0}$ は初期圧力 $(\mathrm{Pa}), \mathrm{t}$ は時間 $(\mathrm{s})$, $\tau$ は排気時定数（s）を示す. 本ガス測定装置は各排気系に 可変流量弁を取り付けており，その弁によって排気時定数と ガス圧を調整することが可能である．Fig. 2 は，試料ガス に空気を用いて可変流量弁を全開にした場合（Setup1）と 調整した場合（Setup2）の全圧の時間変化を示す．Table 2 に示すように各排気時定数は, Setup1で3.5秒, Setup2で 20秒となった．さらにSetup2 について Fig. 3 に示すよう にガス注入を繰り返しおこない，そこから排気時定数を求め てその結果をTable 3 にまとめた．平均排気時定数は 20 秒，標準偏差0.11秒となり，良好な再現性を示した。

\section{3 整形質量スペクトル}

間欠ガス注入による非定常排気過程で得られた質量スペク トルは，ガス圧が一定でないため，このままでは比較評価に 供することができないので，(1)式を用いて数学的に補正す

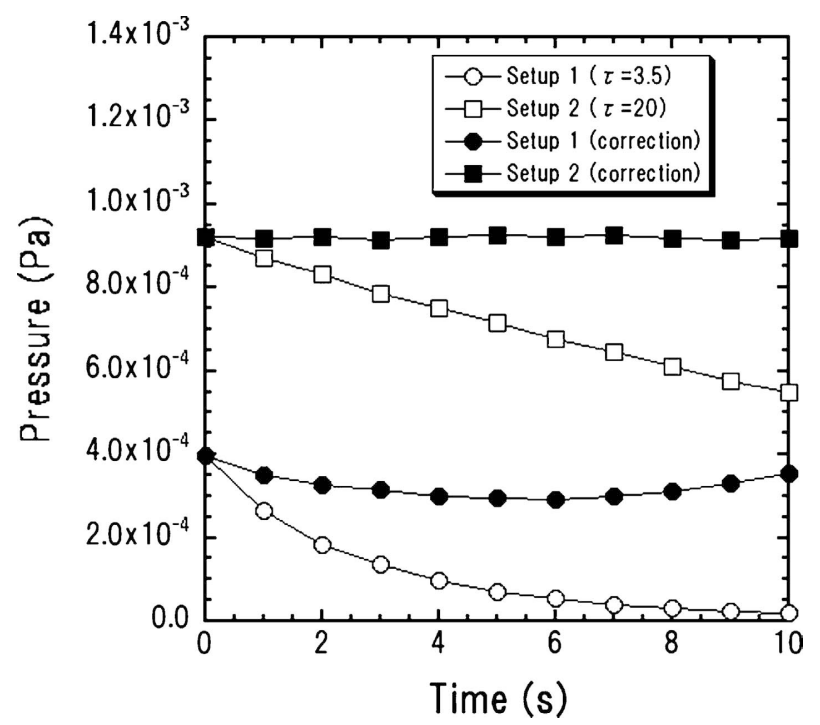

Fig. 2 Measurement pressure and pressure corrected by pumping time constants. "Setup 1" and "Setup 2"are pumping time constants of 3.5 seconds and 20 seconds, respectively. Correction pressure is the same as initial pressure during measurement time in the case of "Setup2".

Table 2 Parameter of curve fitting for pressure.

\begin{tabular}{c|c|c|c}
\hline \hline Setup & $P_{0}$ & $\tau$ & $\mathrm{R}^{*}$ \\
\hline 1 & $3.3 \times 10^{-4}$ & 3.5 & 0.99 \\
\hline 2 & $8.6 \times 10^{-4}$ & 20 & 0.99 \\
\hline
\end{tabular}

$*$ : coefficient of correlation

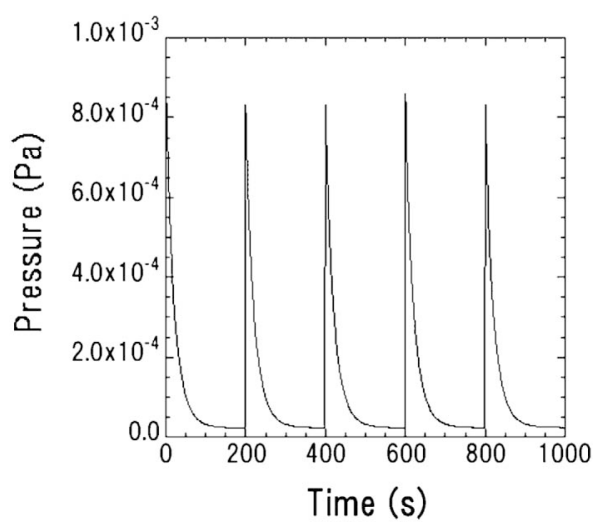

Fig. 3 Measurement pressure of the sample gas by repeated pulse injections. It shows reproducible maximum and minimum pressure, and pumping time constant.

Table 3 Pumping time constant by repeat pulse gas injection.

\begin{tabular}{c|c|c|c|c|c|c|c}
\hline \hline No. & 1 & 2 & 3 & 4 & 5 & Average & S.D. $^{*}$ \\
\hline$\tau$ & 20.1 & 20.1 & 19.9 & 20.0 & 19.9 & 20.0 & 0.11 \\
\hline
\end{tabular}

* S.D. (Standard deviation)

る. 圧力はイオン化電流に比例6)するので，(1)式と同様に 表すことができる。

$$
\mathrm{I}=\mathrm{I}_{0} \exp (-\mathrm{t} / \tau)
$$




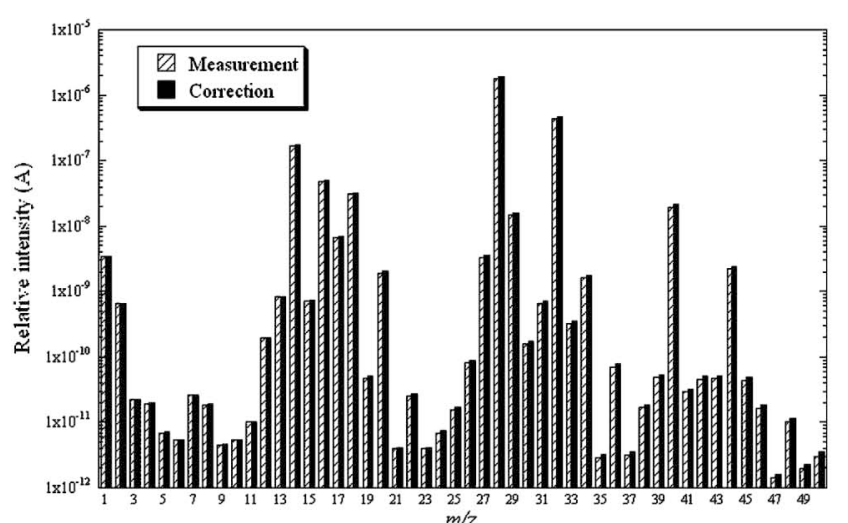

(a)

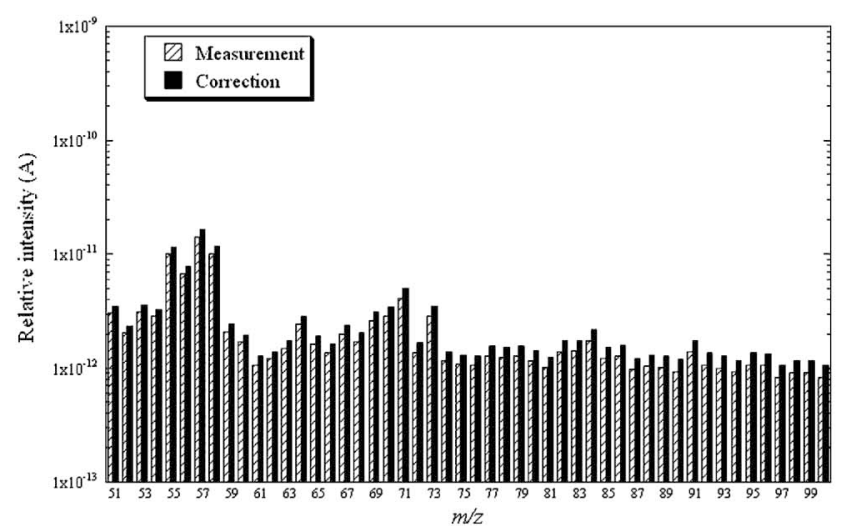

(b)

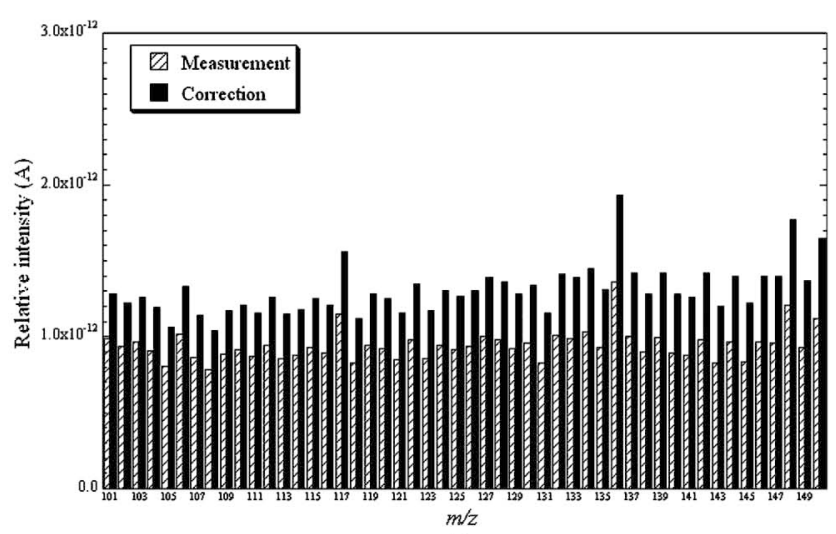

(c)

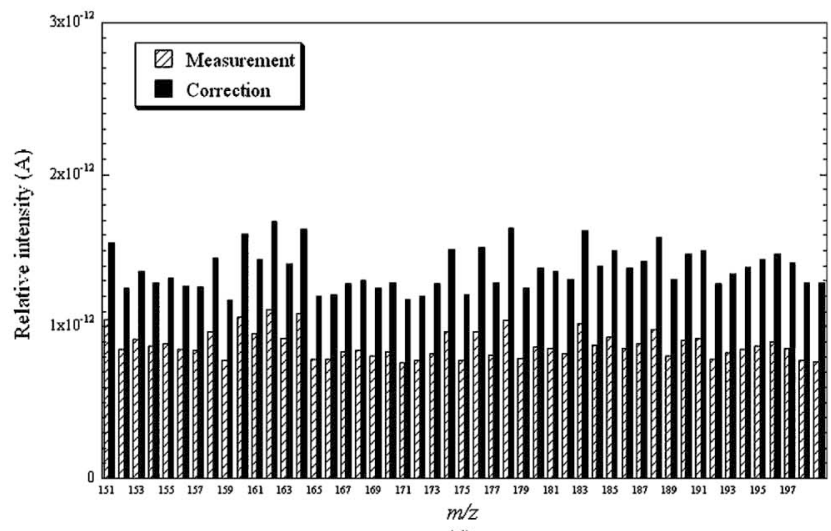

(d)

Fig. 4 Comparison with measurement and correction mass spectrum. Vertical axes of (a) and (b) graphs are logarithmic scale. Vertical axes of (c) and (d) graphs are liner scale. The correction mass spectrum does not change the pattern and increase relative intensity.

Table 4 Numerical value of shaping mass spectrums for $\mathrm{H}_{2}, \mathrm{~N}_{2}, \mathrm{Ar}$ and $\mathrm{CO}_{2}$.

\begin{tabular}{|c|c|c|c|c|c|c|c|c|c|c|c|c|c|}
\hline Gas & \multicolumn{3}{|c|}{$\mathrm{N}_{2}$} & \multicolumn{2}{|c|}{$\mathrm{O}_{2}$} & \multicolumn{4}{|c|}{$\mathrm{Ar}$} & \multicolumn{4}{|c|}{$\mathrm{CO}_{2}$} \\
\hline $\mathrm{m} / \mathrm{e}$ & 14 & 28 & 29 & 16 & 32 & 20 & 36 & 38 & 40 & 22 & 44 & 45 & 46 \\
\hline Shaping mass spectrum & 8.14 & 94.29 & 0.74 & 2.44 & 23.48 & $\begin{array}{c}8.72 \\
\times 10^{-2}\end{array}$ & $\begin{array}{c}3.23 \\
\times 10^{-3}\end{array}$ & $\begin{array}{c}3.74 \\
\times 10^{-4}\end{array}$ & 1.00 & $\begin{array}{c}5.54 \\
\times 10^{-4}\end{array}$ & $\begin{array}{c}3.98 \\
\times 10^{-2}\end{array}$ & $\begin{array}{c}3.62 \\
\times 10^{-4}\end{array}$ & $\begin{array}{c}2.08 \\
\times 10^{-4}\end{array}$ \\
\hline (NIST form) & $(8.63)$ & $(100)$ & $(0.79)$ & $(10.41)$ & $(100)$ & $(8.72)$ & $(0.32)$ & $(0.04)$ & $(100)$ & $(1.39)$ & $(100)$ & $(0.91)$ & $(0.52)$ \\
\hline NIST data & 13.79 & 100 & 0.74 & 21.80 & 100 & 14.62 & 0.30 & 0.05 & 100 & 1.90 & 100 & 1.20 & 0.40 \\
\hline
\end{tabular}

I はイオン化電流 $(\mathrm{A}), \mathrm{I}_{0}$ は初期イオン化電流（A）を示 す。（2)式を変形すると下記の (3) 式のようにイオン化電流 は初期イオン化電流 $\mathrm{I}_{0}$, 圧力は初期圧力 $\mathrm{P}_{0}$ となり, それに 対応して質量スペクトルを整形する.

$$
\mathrm{I}_{0}=\mathrm{I} \exp (\mathrm{t} / \tau)
$$

本装置で得られる整形質量スペクトルは測定時間に対して 適切な排気時定数を設定することが重要である. Setup2の 設定で試料ガスを測定速度 $0.05 \mathrm{~s} / \mathrm{amu}$ で $\mathrm{m} / \mathrm{e}=1$ から 2000 範囲で測定すると, 測定時間 10 秒であるから排気時定数以 下となり測定終了までに装置内に測定に必要なガスが十分に 残っている状態となり適当である. Fig. 4 に室内空気の測 定時の質量スペクトルと整形質量スペクトルを示す. 整形質 量スペクトルは測定時の質量スペクトルのパターンを変え ず，相対強度が高くなっていることがわかり，その後の質量 スペクトルの定性・定量分析などに使用することができる.

\section{4 定性分析}

純空気（ジャパンファインプロダクツ製 $\mathrm{G} 1$ ）を用いて窒 素, 酸素, アルゴン, 二酸化炭素について整形質量スペクト ルと NIST Mass spectra libraryの EI 質量スペクトル そ)との データ比較をおこなった．質量スペクトルは，測定毎の EIQMS の感度変化を補正するため, 各 $\mathrm{m} / \mathrm{e}$ のイオン化電流值 をアルゴン $\mathrm{m} / \mathrm{e}=40$ によって規格化した. NIST の EI デー タは質量スペクトル中の最大電流值を基準として他の付随電 流值を相対值で表している. Table 4 にその結果を示す。 NISTの質量スペクトルに対して, 測定結果の質量スペクト ルが各ガスともよく一致している.したがって, Table 4の 結果より整形質量スペクトルをガス成分の定性分析に用いる ことは有効である.

\section{5 定量分析}

アルゴンと窒素の混合ガスを用いて本ガス測定装置の定量 


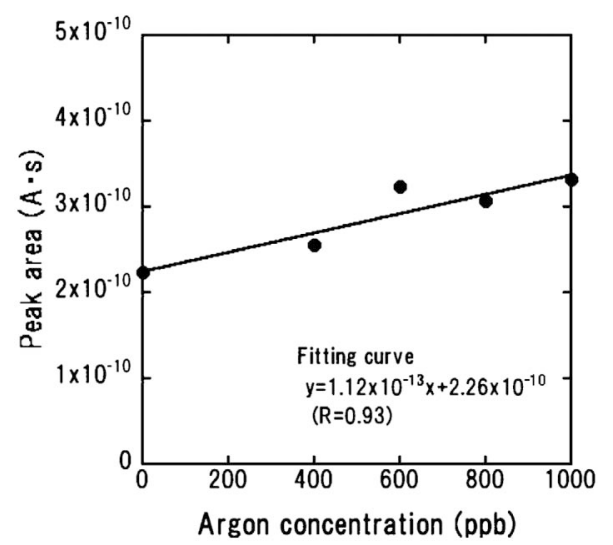

Fig. 5 Results of quantitative measurement as function of argon concentration by pulse gas injection. To evaluate the quantitative performance of pulse gas injection, the argon concentration is measured. The peak area is linear compared with the argon concentration.

性能を評価した。校正ガスは市販のマイクロシリンジ（イ トーマイクロシリンジ MS-N10） と大容量シリンジ（ハミ ルトンスーパーシリンジ S-1000TLL）を用いて作製したア

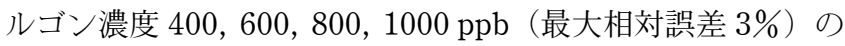
気体を使用した．定量分析に当たってはシグナル強度のバッ クグラウンドからの増加量と時間の積 $(\mathrm{A} \cdot \mathrm{s})$ で評価した.

Fig. 5 に定量分析の結果を示す。アルゴン濃度に対して ピーク面積は線形になっている。 その線形関係から本ガス測
定装置の検出下限界が $100 \mathrm{ppb}$ 以下であることを確認した.

\section{3. ま と め}

高感度ガス分析装置を開発し, 真空排気系の非定常排気過 程の安定性を用いて整形質量スペクトルによるガス分析をお こなった. 間欠ガス注入に拈いても $100 \mathrm{ppb}$ 以下の高感度測 定の見通しを得, 定量分析も可能であることがわかった. 今 後, ガス測定装置の高性能化を進めるとともに分析において 臭気ガスや環境ガスなどのガス成分の同定手法を開発してい く予定である.

\section{〔文献〕}

1) Y. Shida, T. Kasama, S. Kurono, M. Takayama and T. Takahashi: Korenarawakaru Mass spectrometry (Kagaku-Dojin, Kyoto, 2001) Chap. 2, p. 38 [in Japanese]

2) 特許第 4052597 号

3) http://www.nikkin-flux.co.jp/2008/10/post_1.html

4) K. Nakayama: Shinkugizyutsuzitsumudokuhon (Ohmusha, Tokyo, 1994) Chap. 1, p. 8 [in Japanese].

5) Y. Shida, T. Kasama, S. Kurono, M. Takayama and T. Takahashi: Korenarawakaru Mass spectrometry (Kagaku-Dojin, Kyoto, 2001) Chap. 3, p. 65 [in Japanese]

6) H. Kumagai, G. Tominaga, Y. Tuzi, G. Horikoshi: Vacuum Science and Engineering (Syokabo, Tokyo, 1970) Chap. 6, p. 315 [in Japanese].

7) http://www.nist.gov/srd/nistla.htm 